\title{
AGGRESSIVE CHALLENGING BEHAVIOUR IN ADULTS WITH INTELLECTUAL DISABILITY FOLLOWING COMMUNITY RESETTLEMENT
}

\begin{tabular}{|c|c|}
\hline Sabyasachi Bhaumik* & Consultant Psychiatrist ${ }^{1}$ Honorary Senior Lecturer ${ }^{2}$ \\
\hline Joanna Watson & Associate Specialist $^{1}$ Research Associate ${ }^{2}$ \\
\hline John Devapriam & Specialist Registrar ${ }^{1}$ \\
\hline L Bala Raju & Specialist Registrar ${ }^{1}$ \\
\hline Nyunt N Tin & Specialist Registrar ${ }^{1}$ \\
\hline Reza Kiani & Specialist Registrar ${ }^{1}$ \\
\hline Louise Talbott & Speech and Language Therapist ${ }^{1}$ \\
\hline Rachel Parker & Occupational Therapist ${ }^{1}$ \\
\hline Lynne Moore & Practice Development Nurse ${ }^{1}$ \\
\hline Sisir K Majumdar & Consultant Psychiatrist $^{1}$ \\
\hline SK Ganghadaran & Consultant Psychiatrist $^{1}$ \\
\hline Kathryn Dixon & Occupational Therapist ${ }^{1}$ \\
\hline Amitava Das Gupta & Consultant Psychiatrist $^{1}$ \\
\hline Freya Tyrer & Research Fellow in Epidemiology, Trent Research and \\
\hline
\end{tabular}

${ }^{1}$ Leicestershire Partnership NHS Trust, Leicester Frith Hospital, Groby Road, Leicester LE3 9QF

${ }^{2}$ Department of Health Sciences, University of Leicester, 22-28 Princess Road West, Leicester LE1 6TP

${ }^{*}$ author for correspondence

Abstract word count: $146 \quad$ Total word count: 1665 


\section{ABSTRACT}

\section{Background}

Aggressive challenging behaviour is common in adults with intellectual disability (ID) in long-term care facilities. The UK government's commitment to the closure of all facilities has led to concerns over how to manage this behaviour in the community. This study aimed to assess changes in aggressive challenging behaviour and psychotropic drug use in adults with ID following resettlement using a person-centred approach.

\section{Method}

The Modified Overt Aggression Scale (MOAS) was administered to carers of 49 adults with ID prior to discharge from a long-stay hospital and six months and one year after resettlement in the community.

\section{Results}

All areas of aggressive challenging behaviour reduced significantly between baseline and six months following resettlement $(p<0.001)$. This reduction remained (but did not decrease further) at one year follow up.

\section{Conclusions}

Further work is needed to evaluate the role of environmental setting on aggressive challenging behaviour in adults with ID. 


\section{INTRODUCTION}

Aggressive challenging behaviour is common in adults with intellectual disability (ID) (Smith, Branford, Collacott, Cooper, \& McGrother, 1996) and is particularly prevalent among those residing in NHS accommodation (F. Tyrer et al., 2006). The UK government's commitment to the closure of all NHS long-term care facilities by the year 2010 (Department of Health, 2006) has raised concerns about how to manage this behaviour in the wider community, particularly where it risks causing harm to others. As a means of reducing aggressive challenging behaviour, antipsychotic drugs are commonly prescribed in this population (Robertson et al., 2000), but recent evidence suggests that these may not be as effective as previously thought (P. Tyrer et al., 2008).

Assessment of aggressive challenging behaviour after discharge from long-term care facilities is important to assess the threat to self, residents, carers and other members of society. However, few studies have looked at changes in behaviour post-relocation and those that have been carried out show conflicting results (Donnelly et al., 1996; MacLeod, Morrison, Swanston, \& Lindsay, 2002). Similarly the way in which former residents were relocated to the community has not been described, which is likely to be important for the success of future relocation schemes.

The aims of the present study were to assess whether there was a change in aggressive challenging behaviour in adults with ID following resettlement in the community using a person-centred approach. We also aimed to investigate any changes in psychotropic drug use over this time period.

\section{METHODS}


This was a study of the last 51 adult residents to leave a long-stay hospital in Leicestershire and be resettled in the community between 2004 and 2006 . The study was approved by the institutional review board and was conducted under Good Clinical Practice guidelines. Prior to relocating patients a multi-disciplinary group of specialist health and social care professionals met regularly to discuss the intended resettlement process. Residents, their family members (where possible), advocates (for residents who were unable to express their views independently) and formal carers were all involved in the decision-making process. A person-centred approach was adopted whereby residents were encouraged to discuss their preferences and needs, so that suitable placements could be chosen.

Aggressive challenging behaviour was assessed using the Modified Overt Aggression Scale (MOAS) (Yudofsky, Silver, Jackson, Endicott, \& Williams, 1986) (Kay, Wolkenfeld, \& Murrill, 1988). The MOAS was designed to measure four types of aggression: verbal aggression; aggression towards objects; aggression towards self; and aggression towards others, among people with psychiatric disorders. It has since been found to be reliable in people with ID (Oliver, Crawford, Rao, Reece, \& Tyrer, 2007). The scale involves scoring each type of aggressive challenging behaviour as a score ranging from 0 (absence of behaviour) to 4 (severe behaviour). For this study, we used the MOAS to assess aggressive challenging behaviour at baseline (defined as six months prior to discharge from hospital), and at six months and one year following resettlement in the community. Assessments were carried out with the individual's formal carer (members of staff in the hospital or community setting as appropriate) by specialist health professionals. Adults were defined as having aggressive challenging behaviour if they had a MOAS score $\geq 4$. 
Additional information collected included age (on 1 March 2004), sex, severity of ID (clinical diagnoses using ICD-10 criteria (World Health Organisation, 1992)), presence of co-existing health problems and location of resettlement. Information on psychotropic drugs prescribed for mental health problems or challenging behaviour was recorded at baseline and one year after resettlement.

\section{Statistical Analysis}

Statistical analyses were adapted to a repeated measures design. Differences between the prevalence of aggressive challenging behaviour in individuals at baseline, six months post-relocation and one year post-relocation were compared using McNemar's test. Differences between absolute scores on the MOAS scale at baseline and post-relocation were compared using the Wilcoxon signed-ranks test. All analyses were carried out in Stata version 9.0 (StataCorp, 2005).

\section{RESULTS}

The study population initially comprised 51 adults with ID. Two participants were not included in the subsequent analysis because they died before their second assessment. Of those remaining, 36 (73\%) were men (mean age 50.8; range 31-73 years) and 13 (27\%) were women (mean age 49.3; range 35-96 years). All participants were white and generally fell into the more severe end of the ID spectrum: 34 individuals (69\%) had profound ID; 11 (22\%) had severe ID; 3 (6\%) had moderate ID; and one individual (2\%) had mild ID (as determined from clinical diagnoses). Many individuals also had co-existing health problems; 36 (73\%) were incontinent, 2 (4\%) had a hearing impairment; 17 (35\%) had a visual impairment; 30 (61\%) had mobility problems; and 32 (65\%) suffered from epilepsy. 
Aggressive challenging behaviour was common among the study population. At baseline, $76 \%$ of participants had an overall MOAS score of 4 or more (median score 16), and thus fulfilled the criteria for having aggressive challenging behaviour. The use of psychotropic drugs was also common: $67 \%$ of participants were taking psychotropic drugs at baseline (mean number of drugs 1.8), most commonly lowdose antipsychotic agents, which were prescribed to more than half $(55 \%)$ of individuals.

All adults were relocated to supported living accommodation, community residential homes, or nursing homes. The majority of individuals ( $n=38 ; 78 \%$ ) were moved to supported living accommodation (i.e. placements developed through individual needs assessment in collaboration with housing services, support services and the participants themselves) with a mean capacity of 9.7 residents (range 3-7). A further six individuals (12\%) were relocated to residential homes (mean capacity 5.8 residents; range 4-15). The remaining five individuals (10\%) were relocated to nursing homes (mean capacity 14.6 residents; range $5-12$ ).

There was an overall reduction in the prevalence of aggressive challenging behaviour in adults with ID between baseline and six months following resettlement (Table 1). At baseline, $76 \%$ of adults fulfilled the criteria for aggressive challenging behaviour (i.e. MOAS score $\geq 4$ ) compared with $45 \%$ six months post-relocation $(p<0.001)$. Absolute scores on the MOAS scale for all domains of aggressive challenging behaviour also lowered substantially $(p<0.001)$. The change in the prevalence of aggressive challenging behaviour between baseline and six months post-relocation was most apparent in men with ID. Although absolute scores on the MOAS scale lowered significantly in the 13 women studied $(p=0.002)$, the overall prevalence of aggressive challenging behaviour did not $(p=0.18)$. Similarly, a reduction in the prevalence of aggressive challenging behaviour was observed in 
individuals relocated to supported living accommodation, but not in those relocated to community residential or nursing homes (although numbers were small in the latter two groups).

Individually, the majority of participants $(n=39 ; 80 \%)$ showed a reduction in aggressive challenging behaviour between baseline and six months post-relocation as determined by their overall MOAS score (range of decrease: 1 to 16). However, five individuals (10\%) showed no change in aggressive challenging behaviour, and four individuals (8\%) showed a moderate increase in aggressive challenging behaviour (range of increase in MOAS score: 1 to 5). The latter group (whose behaviour worsened) comprised three men (mean age 54.3) and one woman (aged 52) who all moved to supported living accommodation (one with two other residents and three with 15 other residents).

One year following resettlement, the number of participants with aggressive challenging behaviour had further reduced; less than one-third $(n=15 ; 31 \%)$ of individuals fulfilled the criteria for aggressive challenging behaviour. However, this further reduction was not significant at the $5 \%$ level $(p=0.09)$, suggesting a stabilising effect. Similarly, no further reductions in aggressive challenging behaviour were observed in men and women, by age group, or in those who moved to community residential or nursing homes. However, a further reduction was observed in those who moved to supported living accommodation. The use of psychotropic medication remained constant between baseline and one year follow-up.

\section{DISCUSSION}

Our findings revealed a significant reduction in aggressive challenging behaviour in residents of a long-stay hospital six months and one year following resettlement in 
the community. In contrast, no differences were observed in the use of psychotropic drugs between baseline and follow-up. The few studies that have investigated behavioural changes in adults with ID after resettlement to the community are inconclusive. Donnelly et al. (1996) found a significant improvement in the global rating of problem behaviours reported by key workers, but an increase in behaviour rated as 'dangerous' on the Problems Questionnaire (Donnelly et al., 1996). Conversely MacLeod et al. (2002) found an increase in challenging behaviour (rated using the Checklist of Challenging Behaviours) among four individuals resettled into a community project home (MacLeod et al., 2002).

It seems likely that the success of any resettlement depends on appropriate consideration of individual needs. There is no 'one placement fits all' solution; any two individuals undergoing resettlement in the same location are unlikely to have the same outcome. The reduction in challenging behaviour we have observed may in part be due to careful planning and the person-centred approach adopted by care home staff, social workers and other specialist health professionals.

Our study is limited by the small numbers and lack of a control group. We are unable to assess whether a similar reduction in challenging behaviour would have been seen had participants remained in hospital. Some residents were unsettled in the months before resettlement, which may have increased their reported levels of aggressive challenging behaviour at baseline and thus led to an overestimation of the reduction in aggressive challenging behaviour we have observed. We are also unable to control for potential reporting bias as both carers and professionals were committed to the new policy.

Despite these limitations, we hope that this study will highlight the importance of finding appropriate placements for people with ID who are relocated in the 
community. In a broader context, further work is needed to examine the role of the environmental setting in the exacerbation or reduction of aggressive challenging behaviour.

\section{ACKNOWLEDGEMENTS}

We gratefully acknowledge the Leicestershire Partnership NHS Trust and the Department of Health who provided funding for this study. We would also like to thank all clients, carers and health professionals involved in the relocation process. 


\section{REFERENCES}

Department of Health. (2006). Our health, our care, our say: a new direction for community services. London: HMSO.

Donnelly, M., McGilloway, D., Mays, N., Knapp, M., Kavanagh, S., Beecham, J., \& Fenyo, A. (1996). One and two year outcomes for adults with learning disabilities discharged to the community. British Journal of Psychiatry, 168, 598-606.

Kay, S. R., Wolkenfeld, F., \& Murrill, L. M. (1988). Profiles of aggression among psychiatric patients: I. nature and prevalence. Journal of Nervous and Mental Disease, 176, 539-546.

MacLeod, F., Morrison, F., Swanston, M., \& Lindsay, W. (2002). Effects of relocation on the communication and challenging behaviours of four people with severe learning disabilities. British Journal of Learning Disabilities, 30, 32-37.

Oliver, P. C., Crawford, M. J., Rao, B., Reece, B., \& Tyrer, P. (2007). Modified Overt Aggression Scale (MOAS) for people with inellectual disability and aggressive challenging behaviour: a reliability study. Journal of Applied Research in Intellectual Disabilities, 20, 368-372.

Robertson, J., Emerson, E., Gregory, N., Hatton, C., Kessissoglou, S., \& Hallam, A. (2000). Receipt of psychotropic medication by people with intellectual disability in residential settings. Journal of Intellectual Disability Research, 44, 666-676.

Smith, S., Branford, D., Collacott, R. A., Cooper, S. A., \& McGrother, C. W. (1996). Prevalence and cluster typology of maladaptive behaviours in a geographically defined population of adults with learning disabilities. British Journal of Psychiatry, 169, 219-227. 
StataCorp. (2005). Stata User's Guide, Release 9. In. College Station, Texas: Stata Corporation.

Tyrer, F., McGrother, C. W., Thorp, C. F., Donaldson, M., Bhaumik, S., Watson, J. M., \& Hollin, C. (2006). Physical aggression towards others in adults with learning disabilities: prevalence and associated factors. Journal of Intellectual Disability Research, 50, 295-304.

Tyrer, P., Oliver-Africano, P. C., Ahmed, Z., Bouras, N., Cooray, S., Deb, S., Murphy, D., Hare, M., Meade, M., Reece, B., Kramo, K., Bhaumik, S., Harley, D., Regan, A., Thomas, D., Rao, B., North, B., Eliahoo, J., Karatela, S., Soni, A., \& Crawford, M. (2008). Risperidone, haloperidol, and placebo in the treatment of aggressive challenging behaviour in patients with intellectual disability: a randomised controlled trial. Lancet, 371, 57-63.

World Health Organisation. (1992). The ICD-10 classification of mental and behavioural disorders: clinical descriptions and diagnostic guidelines. In. Geneva: World Health Organisation.

Yudofsky, S. C., Silver, J. M., Jackson, W., Endicott, J., \& Williams, D. (1986). The Overt Aggression Scale for the objective rating of verbal and physical aggression. . American Journal of Psychiatry, 143, 35-39. 
Table 1: Aggressive challenging behaviour and psychotropic drug use among former residents of a long-stay hospital following resettlement in the community

\begin{tabular}{|c|c|c|c|c|c|}
\hline Characteristic & Baseline & Six months & $\mathbf{P}^{\dagger}$ & One year & $\mathbf{P}^{\ddagger}$ \\
\hline Aggressive challenging behaviour & & & & & \\
\hline All participants $(n=49)$ & & & & & \\
\hline Prevalence of aggressive behaviour ${ }^{*}(\mathrm{n})$ & $76 \%(37)$ & $45 \%(22)$ & $<0.001$ & $31 \%(15)$ & 0.09 \\
\hline Median overall MOAS score & 16.0 & 3.0 & $<0.001$ & 2.0 & 0.47 \\
\hline Verbal aggression & 4.0 & 0.0 & $<0.001$ & 0.0 & 0.65 \\
\hline Aggression towards objects & 4.0 & 0.0 & $<0.001$ & 0.0 & 0.22 \\
\hline Aggression towards self & 4.0 & 0.0 & $<0.001$ & 0.0 & 0.56 \\
\hline Aggression towards others & 4.0 & 0.0 & $<0.001$ & 0.0 & 0.68 \\
\hline Men $(n=36)$ & & & & & \\
\hline Prevalence of aggressive behaviour $(n)$ & $69 \%(25)$ & $36 \%(13)$ & 0.002 & $28 \%(10)$ & 0.37 \\
\hline Median overall MOAS score & 12.5 & 1.5 & $<0.001$ & 1.0 & 0.86 \\
\hline Women $(n=13)$ & & & & & \\
\hline Prevalence of aggressive behaviour ( $\mathrm{n}$ ) & $92 \%(12)$ & $69 \%(9)$ & 0.18 & $38 \%(5)$ & 0.10 \\
\hline Median overall MOAS score & 16.0 & 4.0 & 0.002 & 3.0 & 0.29 \\
\hline Age $<50(n=25)$ & & & & & \\
\hline Prevalence of aggressive behaviour $(n)$ & $80 \%(20)$ & $48 \%(12)$ & 0.005 & $44 \%(11)$ & 0.71 \\
\hline Median overall MOAS score & 16.0 & 3.0 & $<0.001$ & 3.0 & 0.60 \\
\hline Age $\geq 50(n=24)$ & & & & & \\
\hline Prevalence of aggressive behaviour $(n)$ & $71 \%(17)$ & $42 \%(10)$ & 0.03 & $17 \% \quad(4)$ & 0.06 \\
\hline Median overall MOAS score & 15.0 & 2.5 & $<0.001$ & 0.5 & 0.13 \\
\hline Moved to supported living $(n=38)$ & & & & & \\
\hline Prevalence of aggressive behaviour $(n)$ & $74 \%(28)$ & $50 \%(19)$ & 0.01 & $29 \%(11)$ & 0.03 \\
\hline Median overall MOAS score & 15.0 & 3.5 & $<0.001$ & 1.5 & 0.04 \\
\hline Moved to residential home $(n=6)$ & & & & & \\
\hline Prevalence of aggressive behaviour $(n)$ & $67 \%(4)$ & $0 \%(0)$ & 0.05 & $33 \%(2)$ & 0.16 \\
\hline Median overall MOAS score & 16.0 & 0.0 & 0.05 & 1.0 & 0.09 \\
\hline Moved to nursing home $(n=5)$ & & & & & \\
\hline Prevalence of aggressive behaviour $(n)$ & $100 \%(5)$ & $60 \%(3)$ & 0.16 & $40 \%(2)$ & 0.32 \\
\hline Median overall MOAS score & 16.0 & 9.0 & 0.04 & 3.0 & 0.48 \\
\hline Psychotropic drug use & & & & & \\
\hline Percentage on psychotropic drugs (n) & $67 \%(33)$ & & & $65 \%(32)$ & 1.00 \\
\hline Percentage on antipsychotic drugs (n) & $53 \%(26)$ & & & $55 \%(27)$ & 0.32 \\
\hline (Median BNF equivalent dose ${ }^{\pi}$ ) & $(24 \%)$ & & & $(22 \%)$ & \\
\hline Percentage on antidepressant drugs ( $n$ ) & $24 \%(12)$ & & & $22 \%(11)$ & 0.32 \\
\hline Percentage on hypnotic/anxiolytic drugs & $18 \%(9)$ & & & $18 \%(9)$ & 1.00 \\
\hline Percentage on mood stabilising drugs & $14 \% \quad(7)$ & & & $10 \% \quad(5)$ & 0.16 \\
\hline
\end{tabular}

* aggressive challenging behaviour is defined as an overall MOAS score $\geq 4$

${ }^{\dagger}$ Test for a difference between characteristic at baseline and 6 months after resettlement

₹ Test for a difference between characteristics at 6 months and 12 months after resettlement

" Percent of British National Formulary recommended dose 